Rev. salud pública. 6 (2): 107-139, 2004

Ensayos/Essays

\title{
Participación Comunitaria y Control Social en el Sistema de Salud
}

\author{
Decsi Astrid Arévalo \\ Economista. M. Sc. Economía, M. Sc. Historia. Universidad de los Andes, Bogotá, \\ Colombia. E-mail: decsias@yahoo.com
}

Recibido 4 Mayo 2003/Enviado para Modificación 18 Octubre 2003/Aceptado 10 Marzo 2004

\section{RESUMEN}

En Colombia la Constitución de 1991 estableció la obligatoriedad de promover la participación social. No obstante, la discusión en torno al significado y el alcance de la participación social no fue agotada con la promulgación de la carta constitucional ya que la participación social contiene un alto componente político, es decir, se trata de la transferencia de una parte del poder a los sectores que antes estaban al margen en la toma de decisiones estatales. En la medida en que el Estado ha concebido la estrategia de mercado como la mejor forma de asignar los recursos y los receptores de la política social son considerados como consumidores, el reto es establecer un balance de oferta y demanda para garantizar eficiencia y eficacia en la aplicación de los recursos y transparencia en la gestión pública. De allí que la comunidad de usuarios tiene la misión de velar porque se lleve a cabo una correcta asignación de los recursos provistos por el Estado. Una manera de apreciar esta tendencia es la configuración de las formas de participación. Al evaluar algunos de los resultados de la aplicación de esta estrategia de participación social en salud se pueden destacar tres características: hay importantes avances en la promoción de la participación, pero no en control social; existe dispersión y atomización del control social; y se manifiesta una debilidad de la participación como política institucional. Respecto al primer

\footnotetext{
${ }^{1}$ Los contenidos del artículo se basan en el proyecto "Evaluación y reestructuración de los procesos, estrategias y organismos encargados de adelantar las funciones de financiación, aseguramiento y prestación de servicios del régimen subsidiado", realizado por el Centro de Investigaciones para el Desarrollo-CID, de la Universidad Nacional de Colombia, mediante contrato con el Ministerio de Salud de Colombia (Programa de Apoyo a la Reforma) y con financiación del Banco Interamericano de Desarrollo (BID). Los informes de investigación sobre éste y los restantes temas tratados en el proyecto se encuentran publicados en tres tomos de la colección La Seguridad Social en la Encrucijada, 2002, Universidad Nacional, Facultad de Ciencias Económicas, CID; Ministerio de Salud, Programa de Apoyo a la Reforma. La dirección del Proyecto estuvo a cargo de Óscar Rodríguez Salazar.
} 
tema se puede concluir que ha existido una respuesta favorable por parte los municipios a la obligación de promover las formas organizativas de la comunidad en lo que a salud se refiere. Al tomar en cuenta las acciones desarrolladas en control social el panorama cambia. La convocatoria de las instituciones del sistema a las organizaciones comunitarias es considerablemente baja, al igual que lo es la discusión de los informes presentados por tales organizaciones. De otra parte, se hizo evidente la falta de comunicación entre las diferentes instancias comprometidas en la promoción de la participación y en el control social, situación que se refleja en la presencia de relaciones de naturaleza bilateral, es decir sólo se conoce al interlocutor más directo.

Palabras Claves: Participación comunitaria, sistema de salud, Colombia (fuente: DeCS, BIREME).

\section{ABSTRACT}

\section{Community participation and social control in the health system}

In Colombia, the 1991 Constitution established the obligation of promoting social participation. However, the discussion regarding the significance and scope of social participation is far from being over with the promulgation of the Constitution since social participation has a high political component, i.e., social participation requires the transfer of a part of power to sectors previously excluded from decision taking. As long as the State has conceived the market strategy as the best way to allocate resources and the receptors of social policy are considered as consumers, the challenge is to establish a balance between supply and demand in order to guarantee efficiency and efficacy in the application of resources and transparency in the public administration. Thus, the community of users has the mission of monitoring the correct allocation of State resources. Upon evaluating some of the results of the application of this strategy of social participation in health, three features can be highlighted: there are important advances in the promotion of social participation but not in social control; social control is dispersed and atomized, and participation as institutional policy is weak. Regarding the first aspect, it can be concluded that there has been a favorable response of the municipalities to the obligation of promoting the organizational forms of the community as far as health is concerned. When the actions carried out for social control are taken into account, the outlook varies. The convoking capacity of the institutions of the system to community organizations is considerably low, as well as the discussion of the reports presented by such organizations. On the other hand, the lack of communication between the different instances involved in both promotion of participation and social control became evident, situation which reflects the presence of relationships of bilateral nature, i.e., only the most direct interlocutor is known.

Key Words: Community participation, social control, healthcare system, Colombia, (source: DeCS, BIREME) 
$\mathrm{E}$ n períodos recientes la participación comunitaria ha recibido un decidido apoyo, en especial por ser llamada a constituir un elemento central en los programas sociales, las políticas públicas y los modelos de desarrollo. No obstante, este impulso no ha estado al margen del debate en torno a cómo se puede entender la participación de la comunidad en los asuntos públicos y a cuál sería el objetivo último de esa participación.

Dos puntos de vista resultan ilustrativos del debate. De una parte, la participación se refiere a una expresión de la democracia política y de manera directa a su vinculación con los procesos de desarrollo y de cambio social. Bajo esta consideración, los gobiernos pueden intervenir en el desenvolvimiento socioeconómico integrando a la población en los procesos de planificación y en la ejecución de programas. Otro enfoque sostiene que las prácticas participativas tienen origen en las formas autónomas de organización comunitaria, que son distintas a las promovidas por los organismos gubernamentales y que en la mayoría de las ocasiones actúa en contravía de ellas. Desde esta última visión se considera que la otra perspectiva afirmaría una participación predeterminada y expresada únicamente en la formalidad, es decir, se trataría de un aporte negociable y no una verdadera inserción de la comunidad. Por ello insisten en que la participación que nace de la misma comunidad resulta más activa y por tanto más eficaz (1).

Los gobiernos colombianos le han imputado tres tareas a la participación comunitaria: a) "buscar la reconciliación nacional y la puesta en práctica de mecanismos que den lugar a una relación armónica y duradera entre el Estado y la población, así como entre los diversos sectores que conforman la sociedad" (Decreto 2707 de 1993); b) "instrumento primordial de la vida administrativa, de la acción de la justicia, de la gestión y modernización del estado, de la vida socioeconómica”(2); y c) es importante la asociación de las personas para acceder a la oferta de bienes del Estado, constituir la base de convivencia indispensable para el logro de los objetivos de desarrollo y garantizar la oportunidad para que los ciudadanos desarrollen acciones conjuntas con el Estado. En esta dirección, la participación comunitaria podría considerarse como "un instrumento de política pública para lograr un desarrollo armónico de la sociedad”(2).

Dentro de esta concepción el control social que se promueve se entiende como una "forma de participación que le permite a la gente determinar las condiciones en que se desarrolla la gestión pública (...) de esta forma el control social contribuye a elevar los niveles de eficiencia, 
eficacia, impacto y transparencia de la gestión pública”(3).La participación comunitaria en el ejercicio del control resulta fundamental no sólo para la transparencia de la gestión pública sino también para la construcción de tejido social y el fortalecimiento de la democracia. La integración de los ciudadanos a través de los mecanismos de participación y control social, permite que cada persona se reconozca como ciudadano y en esa medida comprenda sus derechos y sus deberes. De allí que la población podrá generar nuevos compromisos para contribuir al desenvolvimiento del sistema.

\section{INSTITUCIONALIZACION DE LA PARTICIPACIÓN Y EL CONTROL SOCIAL}

Con la Constitución de 1991 el Estado colombiano se definió como democrático y participativo, en esta dirección los artículos 40, 103 y 270 se refieren a la obligación de promover la organización comunitaria. Esta Carta ha sido considerada como el punto de encuentro de distintas tendencias que propendían por el fortalecimiento de la participación de la sociedad; de una parte, se manifestaba el impulso de las comunidades y de las organizaciones no gubernamentales, y de otra, diferentes instituciones estatales abrían espacios para la integración con la comunidad.

En la esfera del Estado la intención de vincular la población a los propósitos de desarrollo se encuentra desde finales de los años cincuenta; pero es a partir de los años setenta cuando se establece como uno de los objetivos gubernamentales. Así, en el plan de las cuatro estrategias se afirma que es preciso integrar los movimientos comunitarios, campesinos, cooperativos y sindicales en un conjunto de medidas que permitan lograr un mayor bienestar "entendido no solo como prestación de servicios básicos sino también como acceso de los grupos populares a la estructura de poder y a la estructura económica a través de su participación en el ingreso nacional” (4). Esta misma idea fue presentada en los programas sociales específicos (alimentación y nutrición, salud y saneamiento ambiental, integración de servicios y participación comunitaria en zonas marginales urbanas, entre otros) del Plan para cerrar la brecha y en los planes de desarrollo posteriores. Parejo a esta intención, en las entidades estatales se crean mecanismos que permiten los vínculos con la comunidad.

Al revisar los antecedentes de la experiencia en la participación comunitaria se encuentra que uno de los más importantes pasos en el camino de su articulación con los cambios estatales fue la creación de las Juntas de Acción 
Comunal, llevada a cabo en 1958 con la puesta en marcha del Frente Nacional. Estas organizaciones comunitarias se entendían como un eslabón mediador de las relaciones entre el Estado y la sociedad a través del cual se pudiera contar con recursos para las comunidades, los cuales sin embargo fueron mediados por los partidos tradicionales, situación que le restó autonomía a la participación comunitaria (5).

Desde la década del setenta los movimientos sociales, no partidistas ni gremiales, asociaban sus reclamaciones al Estado con una exigencia de participación en las políticas sociales. "Los pliegos de las marchas, tomas y paros exigían participación social en las decisiones de programas y proyectos, la administración de empresas y funciones públicas, la concertación de planes de desarrollo locales de los diferentes sectores de política pública e, ingerencia en la orientación sobre a asignación y manejo de los recursos. La recomposición del movimiento social superaba entonces la reivindicación de beneficios al Estado para exigir la concertación y cogestión de políticas de interés colectivo" (5).

Un nuevo impulso a la conformación de procesos organizativos provino de los programas de lucha contra la pobreza. Dentro de estos enfoques se propone "un ataque frontal a la pobreza mediante la movilización del entusiasmo y la acción popular" (6). En esta dirección se promueve en primera instancia la organización comunitaria para la autogestión, la cooperación y el control en la provisión de servicios públicos.

La más reciente intervención estatal en el fortalecimiento de la participación comunitaria se puede comprender a la luz de tres modalidades seguidas por el Estado: a) apertura de los espacios políticos, que comprende la elección popular de alcaldes y creación de las Juntas Administradoras Locales; b) programas estatales específicos como el Desarrollo Rural Integrado-DRI, Plan Nacional de Rehabilitación-PNR y la Red de Solidaridad y; c) relaciones con el mercado.

\section{Apertura de espacios políticos}

La reforma constitucional de 1986 introdujo la descentralización política administrativa como un criterio de organización del Estado. Dentro de la primera iniciativa se inscribe la elección popular de alcaldes, en donde la ingerencia directa de la comunidad en la determinación de las autoridades locales se convierte en un instrumento regulador de las relaciones entre el Estado y los poderes locales. En esta dirección se lograría una mayor presencia estatal en regiones en donde antes estaría ausente, por ello esta figura política 
permitiría: i) institucionalizar el conflicto político y armado; ii) ampliar el espectro político más allá del bipartidismo; iii) ensanchar las posibilidades de participación a formas no tradicionalmente partidistas; iv) provocar cambios en el comportamiento electoral para superar a abstención (7).

Las Juntas Administradoras Locales se crearon como subdivisiones administrativas de los municipios, con funciones consultivas en el presupuesto y de vigilancia en la prestación de los servicios públicos; sin embargo, la Constitución de 1991 les atribuyó un papel más importante en la formulación de planes y programas, el control de las inversión con recursos públicos y la distribución del presupuesto. Esta extensión de funciones abre el espacio para que las Juntas Administradoras Locales-JAL no sólo cumplan un papel administrativo, sino también les da herramientas para una actuación política (7).

\section{Programas estatales específicos}

El DRI, desde su inicio en la administración López Michelsen, tenía prevista la participación comunitaria, toda vez que los planes de asistencia técnica, las propuestas de organización para el mercadeo de productos y la dotación de servicios de salud y educación así lo requería. Bajo estas circunstancias se crearon los comités veredales de beneficiarios, los cuales quedaron insertos en una estructura piramidal que cubría los ámbitos departamental, regional y nacional. Estos comités participaron en la determinación de las necesidades y potencialidades de la comunidad, la elaboración de un plan de prioridades, ayudaron en la ejecución de programa y en la organización de los usuarios (7).

El PNR propone una forma de inserción de la participación de la comunidad a través de los Consejos de Rehabilitación; en ellos las funciones de la comunidad eran canalizar las demandas de la población, difundir y ambientar las políticas, ayudar al establecimiento de las prioridades del plan, identificar y proponer las obras para ser ejecutadas con la participación de las comunidad, colaborar en la organización comunitaria cuando ésta fuera ejecutora de las obras y ejercer la veeduría ciudadana en las contrataciones (7). A partir de esta articulación de la comunidad al Plan se esperaba una eficaz intervención del gobierno en las zonas de violencia, toda vez que una mayor presencia estatal a través de inversión física se interpretaba como la disminución de las zonas de influencia de la guerrilla. 
Por su parte, el trabajo de la Red de Solidaridad se orientó a la lucha contra la pobreza, a partir de la articulación de distintas ofertas de política social. Para su operación configuró una estrategia de control social para permitir la expresión de la comunidad en los campos de participación, negociación y concertación y en el desarrollo de acciones dirigidas al fortalecimiento de la capacidad de interlocución de los ciudadanos con el Estado (8). En esa dirección se establecieron mesas de solidaridad, comités técnicos sectoriales, veedurías ciudadanas y asambleas de beneficiarios.

\section{Relaciones con el mercado}

Las reformas del Estado adelantadas en los últimos veinte años con la intención disminuir del gasto público y alcanzar su mayor eficiencia, han conducido a privilegiar la estrategia de mercado como la mejor forma de asignar recursos. En este escenario la participación comunitaria podría contribuir a la reducción de los gastos públicos, en tanto los individuos o las comunidades se convierten en socios del Estado y cooperan en la financiación de los costos en los cuales se debe incurrir para la satisfacción de las necesidades de la comunidad. Tal articulación tiene como medio privilegiado la formulación y ejecución de proyectos, pues se entiende que con el control social se contribuye a elevar los niveles de eficiencia, eficacia, impacto y transparencia de la gestión pública (9). De otra parte, si los bienes que satisfacen las necesidades son transados en el mercado, el sistema de precios permitiría que los individuos estuvieran mejor informados y que en defensa de sus intereses como consumidores ejercieran control sobre los oferentes.

En la Constitución de 1991 se estableció que el Estado sería garante de la participación de las organizaciones de consumidores y usuarios en el estudio de las disposiciones que les conciernen. Estas asociaciones cuyos antecedentes legales proceden de la década de los ochenta, tienen como misión garantizar la protección, la información, la educación, la representación y el respeto de los derechos de los consumidores de bienes y servicios. Con esta premisa, el proceso de desregulación estatal en la década de los noventa tuvo como contrapartida el fortalecimiento de este tipo de asociaciones, en donde las de mayor impacto han sido las de servicios públicos domiciliarios.

\section{ESTRUCTURA DE LA PARTICIPACIÓN COMUNITARIA Y EL CONTROL SOCIAL EN SALUD}

Entre los antecedentes nacionales en la institucionalización de la participación comunitaria en salud está su promoción para la puesta en marcha de 
programas de control epidemiológico o de inmunización planteados por el Ministerio de Salud en los años sesenta, con el objetivo de crear un espacio para la organización de comités de salud orientados a responder a problemas de orden coyuntural. A principios de los ochenta se establece el Plan de participación de la comunidad en atención primaria de salud, para ello se configuraron comités comunales de salud para participar en la planeación de las acciones de atención primaria y de prestación de servicios de salud. En 1984 se promueve el autocuidado y con ello se vinculan otras organizaciones comunitarias con el propósito de fomentar ese tipo de conductas (10).

Con las transformaciones que se produjeron a partir de la descentralización salud, la promulgación del Estado social de derecho, plasmado en la Constitución de 1991, y la Ley 100 de 1993, se redefine la relación Estadosociedad en el campo de la salud. Una mirada sobre estos cambios debe partir de observar cuál has sido el modelo propuesto por el Estado y continuar con los avances que hasta el momento ha tenido este nuevo esquema en su aplicación.

\section{Enfoque estatal del control social}

La manera como se ha estructurado la participación y el control social en salud está en perfecta correspondencia con las orientaciones que se le han dado al sistema de salud. En las modificaciones recientes al sistema de salud ha prevalecido la visión de mercado que ha orientado las transformaciones del estatales. La preocupación por el ajuste en las finanzas públicas, la presión de demanda por políticas sociales y la confianza en la mayor eficiencia del sector privado frente al público estuvieron presentes en las propuestas de los legisladores que transformaron el sistema de salud. La apertura del sistema de aseguramiento en salud al sector privado, la creación de los subsidios a la demanda y la aplicación de la técnica de focalización constituyeron las estrategias de reforma; con ello se considera que el sistema de salud puede operar como un mercado tradicional, en el cual a los demandantes con menor capacidad de pago se les puede asignar recursos para que accedan a los servicios. En esta misma perspectiva, la ampliación de la competencia en el mercado asegurador mejoraría la calidad en la oferta de aseguramiento, pero también en la de servicios de salud.

Con esta dirección se produce un cambio importante en las condiciones de demanda de políticas públicas en general y servicios de salud en particular, puesto que las presiones para acceder a tales políticas son filtradas por la aplicación de mecanismos de mercado. Para tener derecho a los servicios de 
salud se debe contar con un carné de aseguramiento, en el caso de la población de bajos ingresos ese derecho se obtiene a través del reconocimiento de una limitación presupuestal para acceder; de ahí que las posibilidades de contar con atención en salud dependen exclusivamente de variables como ingreso y precios. Sin embargo, los legisladores parecen aceptar que se trata de un mercado imperfecto y por ello se precisan mecanismos de regulación.

A partir de una visión defensora de los mecanismos de mercado se afirma que dentro de la lógica de funcionamiento de un mercado imperfecto debe tenerse en cuenta el carácter incierto del ambiente en que se toman las decisiones. La incertidumbre ilustra una falta de información sobre el futuro, sobre el comportamiento de los individuos y sobre sus preferencias, esta condición conduce a que cada uno manipule la información de la cual dispone, con lo que obtiene una fuente de poder en la negociación. En el caso de los servicios de salud la incertidumbre y la asimetría de la información son características casi evidentes; en términos de la disponibilidad de información desde la perspectiva del individuo se desconocería la totalidad de la oferta de servicios, sus calidades y sus precios, así como los elementos técnicos (tratamiento más adecuado); desde el punto de vista de las entidades prestatarias de los servicios no se conoce completamente las condiciones de salud y de hábitat del individuo (11). En estas condiciones el funcionamiento del sistema resulta ineficiente.

Desde otra perspectiva teórica se entiende que las limitaciones dependen más de la lógica de los actores que de la falta de información. Así la búsqueda de beneficio por parte de los empresarios conduce al establecimiento de redes que desbordan el ámbito económico, pues están ligados a la construcción social de las instituciones y al régimen de acumulación (12). De esta manera la relación entre los distintos agentes no es necesariamente el de la competencia sino que puede dar lugar a la repartición del mercado o la lucha por el control monopólico, o simplemente la formación de una estructura de mercado en la que la empresa dominante lleva la iniciativa en materia de precios, innovaciones y distribución, convirtiéndose en un punto de referencia para las demás entidades.

Sin embargo, siguiendo el enfoque de mercado el gobierno ha establecido diferentes formas de control orientadas a regular el funcionamiento del mercado y combatir la corrupción, y es entre ellas que se encuentran la promoción de la participación social y el ejercicio del control por parte de la comunidad. En la concepción de este sistema la comunidad se asimila al conjunto de individuos o competidores por los recursos y beneficios de las políticas públicas, realizadas mediante la asignación de presupuestos focalizados y los 
subsidios a la población (13). Igualmente, como la prestación de servicios de salud se pretende sostener en un sistema de mercado equiparable al de cualquier otro bien, los demandantes del producto deben tener alguna injerencia en el funcionamiento de dicho mercado.

Promoción de la participación comunitaria

Con la nueva orientación del sistema de salud, el primer mecanismo de participación se establece con el Decreto 1216 de 1989 que crea los Comités de Participación Comunitaria-Copacos) como una respuesta a los principios de la descentralización. Sin embargo es con la Ley 10 de 1990 con la que se amplía la esfera de participación y se brinda a la comunidad la oportunidad de participar en las juntas directivas de los organismos de salud conformados como establecimientos públicos. Luego, con el decreto 1416 de 1990 se avanza, con respecto al 1216/89, al incorporar en la conformación de los Copacos al jefe de la dirección de salud municipal o departamental y al sector educativo.

Por medio del decreto 1416/90 se creó una estructura piramidal de la participación comunitaria teniendo como eje los organismos de prestación de servicios. Con este decreto los individuos podrían hacer uso de la participación comunitaria a través de la conformación de asociaciones de usuarios o de sus representantes en las juntas directivas de las Instituciones Prestadoras de Servicios-IPS públicas o mixtas, Copacos, y consejos comunitarios. Se estipuló que en cada institución prestadora de servicios de salud se tendría el espacio para constituir asociaciones de usuarios.

Los Copacos debían funcionar en todos los organismos o entidades de prestación de servicios de salud de los niveles primero y segundo, y contarían con representación de las asociaciones de usuarios. Los miembros de la comunidad que participarían en las juntas directivas de las IPS serían elegidos de entre aquellos que hacen parte de los Copacos de cada institución. En los consejos comunitarios, convocados por cada dirección local del sistema de salud, participarían de tres a seis miembros elegidos por y entre los representantes de las organizaciones de la comunidad en las juntas directivas de los organismos o entidades de salud.

Con esta jerarquización de los mecanismos de participación se esperaba cubrir todos los ámbitos del sector, pues se cumpliría con las tareas de transmisión de información, vigilancia en el cumplimiento de los acuerdos y de las normas, ingerencia en la toma de decisiones y en los planes de desarrollo del sector. 
En el decreto 1757/94 se parte de que uno de los fundamentos del sistema de seguridad social en salud es la participación social y la concertación, bajo la premisa de que todos los integrantes del sistema tienen el derecho y el deber de participar. De conformidad con el artículo 103 de la constitución en este Decreto se considera que: “el Estado contribuirá a la organización, promoción y capacitación de las asociaciones profesionales, cívicas, sindicales, comunitarias, juveniles, benéficas o de utilidad común no gubernamentales, sin detrimento de su autonomía, con el objeto de que constituyan mecanismos democráticos de representación en las diferentes instancias de participación, concertación, control y vigilancia de la gestión pública que se establezcan”. Además se le otorgan mayores responsabilidades a las instituciones del sistema para impulsar la participación comunitaria y canalizar las peticiones de la comunidad.

A través de este decreto se establecieron dos formas de participación en salud: participación social y participación en las instituciones del Sistema General de Seguridad social en Salud-SGSSS. En la primera quedaron comprendidas la participación ciudadana, referida a los individuos y la comunitaria, correspondiente a las organizaciones comunitarias.

Pese a que la participación ciudadana es entendida como "el ejercicio de los deberes y derechos del individuo para propender por la conservación de la salud personal, familiar y comunitaria y aportar a la planeación, gestión, evaluación y veeduría en los servicios de salud”, los mecanismos para llevarla a cabo se limitan únicamente al sistema de quejas y reclamos. Por su parte, en la participación comunitaria el único espacio previsto es el Copaco, integrado por: el alcalde o su representante, el jefe de la dirección local de salud, el director de la IPS estatal más representativa del municipio y un representante por cada forma de organización social y comunitaria.

En el caso de la participación en las instituciones del SGSSS se contempló la conformación de asociaciones de usuarios y su representación en las juntas directivas de las Entidades Promotoras de Salud-EPS e IPS de carácter público o mixto, los Copacos, los Consejos Territoriales y los comités de ética hospitalaria de las IPS públicas o mixtas.

Las alianzas o asociación de usuarios fueron concebidas como agrupaciones de afiliados del régimen contributivo y subsidiado del SGSS que tienen derecho a utilizar unos servicios de salud de acuerdo con su sistema de afiliación y que velarán por la calidad del servicio y la defensa del usuario. De este tipo de organización quedan excluidos los vinculados y los usuarios que 
no son sujeto de subsidio en salud, pero que tampoco cuentan con una afiliación al régimen contributivo; para el grupo de vinculados el gobierno preveía promover "su organización como demandantes de servicios de salud, sobre las bases de las formas de organización comunitaria".

En conjunto, la participación social se expresaría en los procesos gestionarios de planeación y en la veeduría. El diseño y la gestión de los planes de salud deberían ser concertados con los diferentes sectores sociales, no obstante, para ello no se estipularon los mecanismos a través de los cuales se llevaría a cabo. Para el proceso de veeduría en salud se establecieron tres niveles de canalización: ciudadano, comunitario e institucional. El primero se realiza por intermedio del servicio de atención a la comunidad de la Dirección Local de Salud-DLS, el segundo a través de los Copacos y el tercero mediante las asociaciones de usuarios, comités de ética médica y las juntas directivas de las EPS e IPS. La veeduría puede ser ejercida por los ciudadanos individualmente o a través de cualquier tipo de asociación, gremio o entidad pública o privada del orden municipal, departamental o nacional.

En la investigación adelantada para evaluar el Régimen Subsidiado se estudiaron cerca de 100 municipios de categorías 1 a 6 ( 1 corresponde a los más desarrollados) y se utilizaron diversos métodos de análisis (14). Para el diagnóstico del ejercicio del control social en el régimen subsidiado se aplicaron cuatro instrumentos para determinar las acciones que se adelantan en promoción de la participación comunitaria y de control social por parte de la comunidad: uno destinado a las Direcciones Locales de Salud; otro destinado a las IPS; el tercero se aplicó a los personeros, para identificar su papel como canalizadores de las quejas de la comunidad y, un formulario para las organizaciones comunitarias.

Utilizando el método de análisis de correspondencias múltiples, se observó que los elementos de promoción de la participación comunitaria se encuentran asociados a los municipios grandes. El grado de desarrollo institucional de los municipios se constituye en un factor determinante para impulsar la participación comunitaria. Los bajos niveles de capacitación técnica, de disponibilidad de personal idóneo y el desconocimiento de la legislación actúan en contra del compromiso institucional que deben tener las entidades del sector con respecto a la promoción de la participación comunitaria.

Una primera forma de aproximarse al grado de institucionalización que tiene la promoción de la participación comunitaria en el municipio es preguntarse por la existencia de una oficina encargada de tal labor (Figura 1). 


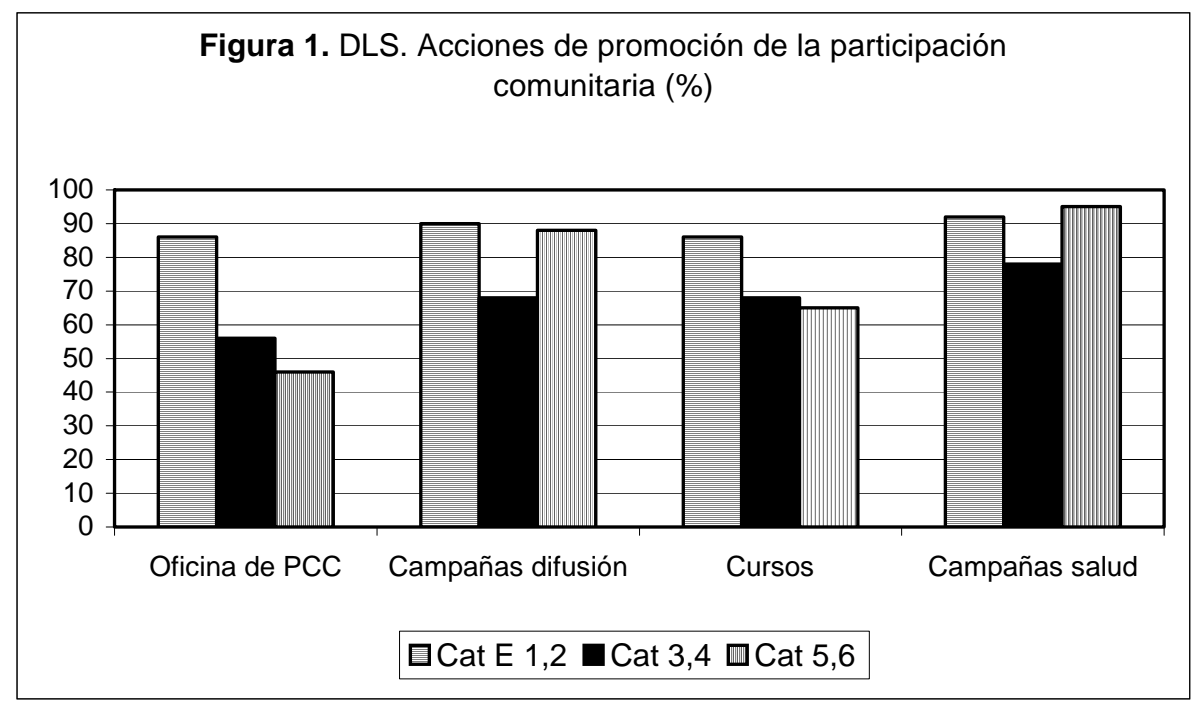

Se observó que en un poco más de las tres cuartas partes de los municipios se ha encargado a una sección de la administración pública para que promueva la vinculación de los ciudadanos a los programas estatales. No obstante, es un fenómeno con importantes diferencias entre las distintas categorías municipales, es evidente que a mayor tamaño del municipio hay una más alta proclividad a la creación de una Oficina de Participación CiudadanaPPC: en los municipios de categorías especial, E 1 y 2 el $86 \%$ cuenta con una oficina municipal, mientras que esto sucede apenas en el $48 \%$ de los municipios de categoría 5 y 6.

Las DLS han asumido un papel dinámico en este proceso, en los municipios grandes el $72 \%$ de las oficinas creadas lo ha sido por parte de esta dirección, mientras que en los pequeños el valor es de $12 \%$, en éstos últimos la alcaldía contribuye con el $12 \%$.

Si bien no en todos los casos se hacen campañas para difundir la participación, de todas maneras las direcciones locales o las oficinas encargadas de la promoción de la participación comunitaria establecen contactos con la comunidad ya sea a través de la entrega de folletos (35\% de los municipios) o por medio de anuncios avisos en la radio o la prensa local; pero la principal es- 
trategia es la visita a las comunidades, en esta actividad se encontró el 62 \% de los municipios.

Un tercer frente de acciones en promoción de la participación son los cursos dictados por las DLS. En el conjunto de municipios se encuentra que el sistema general de seguridad social, el régimen subsidiado la organización comunitaria son los temas tratados con mayor frecuencia; los más específicos de organización social en salud de control social son menos recurrentes, en el caso de los municipios de categorías 3 y 4 son prácticamente inexistentes.

En cuanto a las campañas de salud que involucran participación de las comunidades se encuentra que la casi totalidad de los municipios desarrolla alguna actividad. Se destacan en particular las acciones con los centros educativos, con grupos de la comunidad (barrios y veredas) y con beneficiarios de programas sociales. Este componente de impulso a la participación comunitaria es quizá el más desarrollado en los municipios, toda vez que tiene mayor antigüedad, por cuanto ha estado ligado a los programas del Plan de Atención Básica-PAB, a las acciones desarrolladas por las IPS; por tanto es una de las acciones más apropiadas para apoyar los procesos de conformación de control social.

En lo que se refiere a la conformación de organizaciones comunitarias que se ocupan del control social se encuentra un elevado porcentaje de municipios en los cuales se ha creado al menos una de esas organizaciones. En correspondencia con la mayor cantidad de acciones de promoción de la participación comunitaria desarrolladas por los municipios de categoría E, 1 y 2, se encuentra que en ellos existe un mayor número de organizaciones comunitarias en los distintos grupos: veedurías, asociaciones de usuarios y Copacos. En contraposición, los municipios pequeños alcanzan un bajo registro en la existencia de organizaciones comunitarias como se puede apreciar en la Figura 2.

Es preciso anotar que los municipios medianos y pequeños acusan un elevado nivel de desconocimiento sobre la existencia de las organizaciones comunitarias. Resulta bastante común que en la mayoría de estas localidades no se lleve a cabo registro alguno sobre tales organizaciones, situación que ilustra la falta de comunicación entre la oficina de participación comunitaria y las otras entidades del sector salud. 


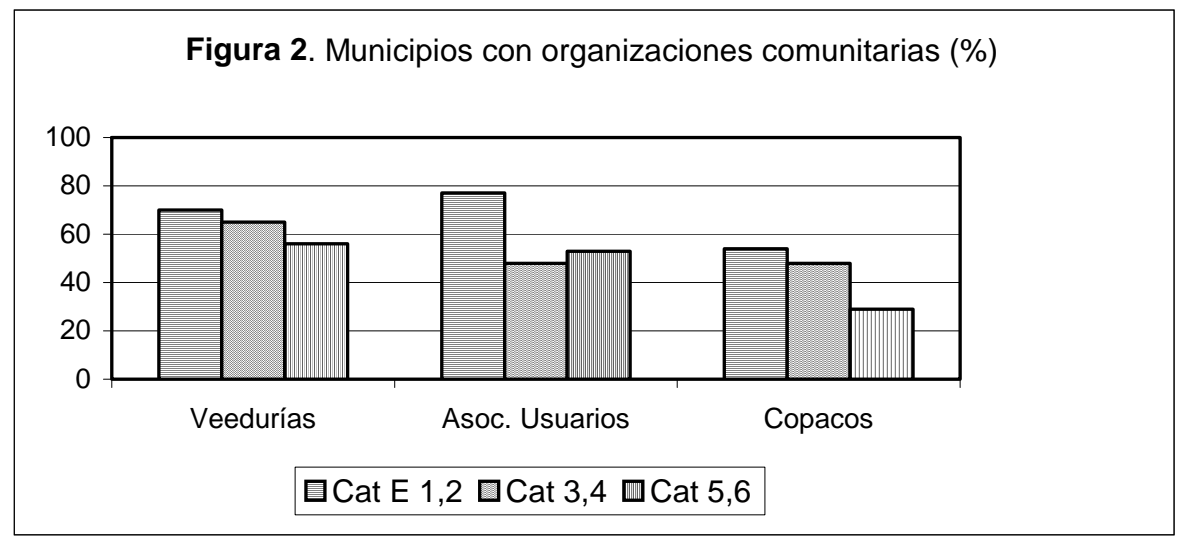

Al considerar la información disponible se encuentra que en general las organizaciones comunitarias son de reducido tamaño: las asociaciones de usuarios se ubican mayoritariamente en el rango de menos de 10 miembros en todas las categorías de municipios, sólo en caso de los grandes municipios se encuentran asociaciones de más de 25 miembros.

Si se tiene en cuenta la información brindada por las IPS y las Administradoras del Régimen subsidiado-ARS se encuentra que en cerca del $80 \%$ de las IPS existe al menos una asociación de usuarios (Figura 3); en un porcentaje menor se han creado comités o comisiones con participación de la comunidad que se ocupan de tareas similares a las desarrolladas por las asociaciones. Sólo en un $10 \%$ de las IPS encuestadas no se encontró ningún tipo de organización comunitaria.

Con respecto a las ARS se observa que el porcentaje es más bajo que el de las IPS, pero también se hallan otras formas organizativas en el $40 \%$ de las instituciones estudiadas, las cuales tienen que ver básicamente con formación de líderes. Entre las principales actividades en las cuales las ARS promueven la participación comunitaria están las de promoción y prevención (en el 43 \% de las entidades), trámite y solución de quejas (43 \%) afiliación y carnetización (31\%), comité técnico científico (22\%) y planeación de los servicios (22 \%). Esta distribución de los ámbitos de promoción de la participación comunitaria dejan ver una tendencia más operativa que de control. 


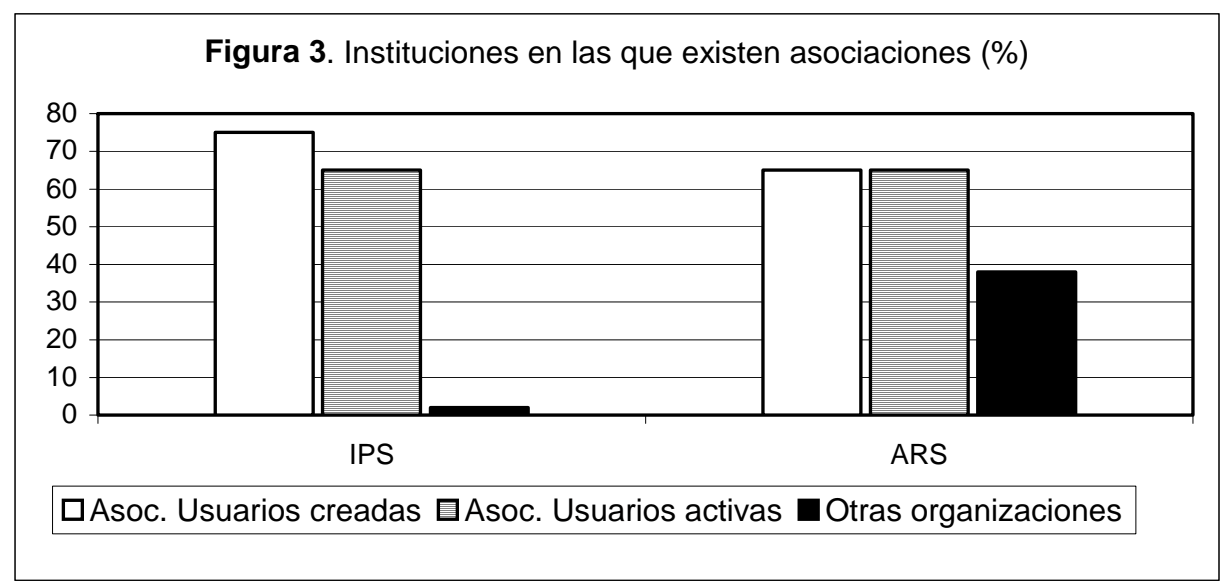

Un actor que se ha sumado a la PPC en los municipios es el personero. En algunos municipios es la Personería la que ha tomado a su cargo la promoción de la organización comunitaria, la que en este caso no está ligada exclusivamente a salud, sino desarrollada en el marco de las veedurías de la gestión pública o de la prestación de servicios públicos domiciliarios.

\section{Ejercicio del control social}

El ya citado artículo 103 de la Constitución, define la participación social en salud como un proceso de interacción social para intervenir en las decisiones de salud respondiendo a intereses individuales (participación ciudadana) y colectivos (participación de las organizaciones comunitarias) en las decisiones de planeación, gestión, evaluación y veeduría en servicios de salud. Frente a ello la administración municipal tiene la obligación crear los mecanismos de participación social y la obligación de dirigir y fortalecer la intervención en la esfera de la toma de decisiones. Por medio de la Ley 100/93 se estableció que la comunidad organizada debía participar con las entidades públicas municipales en la planeación, toma de decisiones y control de las acciones de seguridad social en salud, directriz que fue reglamentada mediante el decreto 1757/94.

$\mathrm{Al}$ observar las funciones que le establece el decreto 1757/94 a las alianzas o asociaciones de usuarios se encuentra que la mayoría de ellas se refieren a servir como flujo de información, lo que implica que sus usuarios co- 
nozcan el sistema y que puedan informar a las instituciones sobre los requerimientos de sus socios, algunas funciones de vigilancia y de veeduría mediante sus representantes ante las EPS y/o ante las oficinas de atención a la comunidad (vigilar que las decisiones tomadas se cumplan que la tarifas y cuotas correspondan a las condiciones socioeconómicas de los distintos grupos) y de decisión a través de las juntas directivas para proponer y concertar las medidas necesarias para mantener y mejorar la calidad de los servicios y atención al usuario.

Entre las funciones estipuladas a la veeduría están las contribuir a una adecuada gestión por parte de los organismos de salud, propiciar decisiones saludables, fomentar el compromiso de la colectividad, velar por una utilización adecuada de los recursos, coordinar con todas las instancias de vigilancia y control la aplicación de las normas e impulsar veedurías como mecanismo de educación para la participación.

Control comunitario. Una de las primeras acciones sobre las cuales se indagó fue la presentación de informes. En términos porcentuales se aprecia que la entrega de informes es mayor en las IPS que en las DLS en todas las categorías de municipios; esta situación muestra una mayor cercanía entre las directivas de las IPS y sus asociaciones que entre las DLS y las suyas. En el caso de las IPS esta relación obedece en parte al tamaño de las instituciones, así en las IPS de los municipios de categorías 3 y 4 como en los de 5 y 6 se expresa una mayor integración; sin embargo, buena parte de las relaciones allí expresadas tienen un fuerte carácter informal en tanto un importante número de informes son verbales y no escritos. En las instituciones de mayor tamaño hay más insistencia en la presentación de informes escritos, en la intención de lograr un mayor grado de institucionalización de la participación comunitaria; de igual forma es preciso tener en cuenta en los municipios de categorías Especial, 1 y 2 se encuentras hospitales de niveles 2, 3 y universitario en los cuales los temas a discutir revisten mayor envergadura y una mayor preparación por parte de los miembros de las asociaciones.

Por su parte, en las DLS se evidencia, aunque bajo, un crecimiento en el número de municipios en los que las veedurías entregan informes. Como se puede apreciar en la figura siguiente, en términos porcentuales son los municipios grandes en los cuales habría un mayor contacto entre veedurías y DLS especialmente en el último año, sin embargo la distancia con las otras categorías municipales no resulta elevada. 


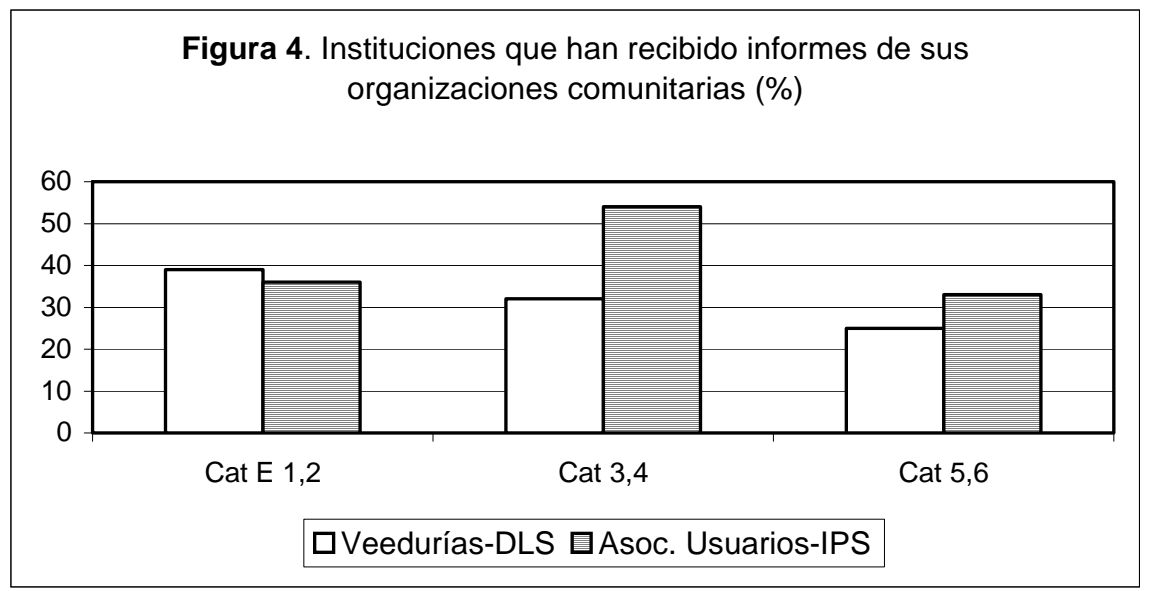

Esta situación ilustra la lentitud con que se verifican los cambios en el proceso de control social, toda vez que ello requiere no sólo del conocimiento sobre el funcionamiento del régimen sino también requiere fortalecimiento de las capacidades de participación social de la comunidad. De otro lado, el alto porcentaje de municipios en los cuales la DLS no recibe informes de las veedurías deja un amplio campo de acción a las actividades de promoción del control social y solidificación del proceso organizativo de la comunidad, puesto que si bien se han hecho grandes esfuerzos en el establecimiento de veedurías, los resultados de su control deben poder servir como elemento de discusión entre los actores el sistema y revertir en la planeación del desarrollo sectorial en el municipio.

La presentación de informes por parte de las organizaciones se convierte en un importante medio de diálogo con las instituciones. Se encontró que un elevado porcentaje de IPS discute los informes presentados por sus asociaciones. Al tomar en cuenta los temas abordados en los informes se observa que los más frecuentes tienen que ver con el acceso a los servicios, la atención de reclamos y la capacidad operativa de la IPS, circunstancia que da muestra de una preocupación directa de las asociaciones por lograr que la población pueda hacer uso de los servicios de salud. Con menor frecuencia están los temas de planes de salud del municipio y la elección de representante comunitario a la Junta Directiva de la IPS. Con muy baja participación aparecen las críticas sobre la presencia de obstáculos al control social, vale la pena señalar este punto en tanto es una muestra de las dificultades en la interacción entre la comunidad y las instituciones (Tabla 1). 
De la discusión de los informes, en general se deriva una acción positiva frente a las críticas. Los temas de acceso a los servicios y respuesta a los reclamos fueron discutidos en todos los casos, no así el resto de los temas.

Tabla 1. Temas de los informes presentados por las asociaciones

\begin{tabular}{|c|c|c|c|c|c|c|c|c|c|c|}
\hline \multirow{3}{*}{ Temas } & \multirow{2}{*}{\multicolumn{3}{|c|}{$\begin{array}{l}\text { Abordados } \\
\text { Categorías } \\
\text { Municipales }\end{array}$}} & \multirow{2}{*}{\multicolumn{3}{|c|}{$\begin{array}{c}\text { Discutidos/abordados } \\
\text { Categorías Munici- } \\
\text { pales }\end{array}$}} & \multicolumn{4}{|c|}{ Soluciones en el conjunto de IPS } \\
\hline & & & & & & & \multirow[t]{2}{*}{$\begin{array}{l}\text { Correc } \\
\text { tivos }\end{array}$} & \multirow[t]{2}{*}{ Traslado } & \multirow[t]{2}{*}{$\begin{array}{c}\text { C. } \\
\text { Proceso }\end{array}$} & \multirow[t]{2}{*}{ Ninguna } \\
\hline & 1,2 & 3,4 & 5,6 & 1,2 & 3,4 & 5,6 & & & & \\
\hline Acceso servicios & 92 & 80 & 57 & 100 & 100 & 100 & 64 & 15 & 11 & 10 \\
\hline $\begin{array}{l}\text { Respuesta } \\
\text { reclamos }\end{array}$ & 50 & 20 & 71 & 100 & 100 & 100 & 84 & 8 & 0 & 8 \\
\hline $\begin{array}{l}\text { Capacidad IPS } \\
\text { Elección }\end{array}$ & 75 & 40 & 14 & 83 & 89 & 50 & 59 & 85 & 17 & 16 \\
\hline $\begin{array}{l}\text { representante } \\
\text { Planes salud }\end{array}$ & 25 & 60 & 43 & 89 & 67 & 100 & 78 & 0 & 11 & 11 \\
\hline $\begin{array}{l}\text { municipio } \\
\text { Obstáculos }\end{array}$ & 25 & 60 & 0 & 83 & 67 & 0 & 67 & 0 & 0 & 33 \\
\hline control & 17 & 40 & 14 & 60 & 100 & 0 & 20 & 40 & 0 & 40 \\
\hline
\end{tabular}

Las respuestas positivas a los tópicos abordados en los informes se presentan fundamentalmente en la respuesta a reclamos y la elección de representante comunitario, en los que se aplican correctivos. Por su parte el acceso a los servicios y la capacidad operativa de la IPS muestran una más baja capacidad de respuesta de las instituciones, pues en un poco más de la mitad de las instituciones se aplican correctivos y en cerca del $10 \%$ se cambian los procedimientos. Esta situación se explica, en parte, por las condiciones financieras de las IPS, en las que la escasez de insumos y la restricción a los servicios de salud se constituyen en una alternativa para continuar funcionando.

En el caso de las DLS se evidencia una menor proclividad que en las IPS a discutir los informes presentados. Entre los temas de crítica más frecuentes en su orden están: sisbenización, carnetización, cumplimiento de las responsabilidades por parte de las ARS, programas de afiliación, acceso a los servicios y explicación de derechos a los beneficiarios del régimen subsidiado. La prioridad en estos temas de crítica deja ver que al igual que en las IPS la preocupación central de las organizaciones comunitarias es el problema del acceso real a los servicios de salud y en particular el de los usuarios del régimen subsidiado. No obstante, la aparición de temas como cumplimiento de las ARS y, aunque en menor grado, manejo financiero de los recursos del régimen subsidiado y obstáculos al ejercicio del control social ponen en evi- 
dencia una aproximación al control que va más allá de demandar mayores servicios para la población (Tabla 2).

Tabla 2. Temas de crítica en los informes presentados por las veedurías a las DLS (\%)

\begin{tabular}{|c|c|c|c|c|c|c|c|c|c|c|}
\hline \multirow{3}{*}{ Temas } & \multirow{2}{*}{\multicolumn{3}{|c|}{$\begin{array}{l}\text { Abordados } \\
\text { Categorías } \\
\text { Municipales }\end{array}$}} & \multirow{2}{*}{\multicolumn{3}{|c|}{$\begin{array}{c}\text { Discutidos/abordados } \\
\text { Categorías } \\
\text { Municipales } \\
\end{array}$}} & \multicolumn{4}{|c|}{ Soluciones en el conjunto de IPS } \\
\hline & & & & & & & \multirow[t]{2}{*}{$\begin{array}{l}\text { Correc } \\
\text { tivos }\end{array}$} & \multirow[t]{2}{*}{ Traslado } & \multirow[t]{2}{*}{$\begin{array}{c}\text { C. } \\
\text { Proceso }\end{array}$} & \multirow[t]{2}{*}{ Ninguna } \\
\hline & 1,2 & 3,4 & 5,6 & 1,2 & 3,4 & 5,6 & & & & \\
\hline Proceso Sisben & 100 & 100 & 75 & 83 & 100 & 67 & 57 & 7 & 14 & 7 \\
\hline Programa afiliación & 64 & 100 & 100 & 57 & 100 & 50 & 75 & 13 & 0 & 13 \\
\hline Carnetización & 91 & 100 & 100 & 100 & 100 & 75 & 53 & 27 & 0 & 20 \\
\hline Interferencia & & & & & & & & 0 & & \\
\hline política en afiliac. & 100 & 50 & 100 & 36 & 100 & 0 & 20 & & 20 & 60 \\
\hline Cumplimiento ARS & 82 & 100 & 100 & 78 & 100 & 75 & 58 & 33 & 8 & 0 \\
\hline Acceso servicios & 100 & 100 & 100 & 64 & 100 & 75 & 75 & 17 & 0 & 8 \\
\hline Respuesta & & & & & & & & & & \\
\hline reclamos & 55 & 100 & 75 & 67 & 100 & 67 & 100 & 0 & 0 & 0 \\
\hline $\begin{array}{l}\text { Obstaculos co } \\
\text { social }\end{array}$ & 55 & 100 & 25 & 83 & 100 & 100 & 88 & 0 & 0 & 13 \\
\hline
\end{tabular}

El grado de respuesta de las DLS a las críticas puede ser un aliciente para seguir profundizando en esta metodología por parte de las organizaciones, puesto que en la mayoría de los casos la aplicación de correctivos supera el $60 \%$, además en el tema de respuesta a los reclamos la respuesta de la DLS en todos los casos discutidos ha sido la aplicación de correctivos.

Del total de organizaciones encuestadas la tercera parte manifestó entregar informes a los demás actores del sistema. En concordancia con las relaciones establecidas a través de las convocatorias, en la entrega de informes se evidencia una mayor relación de las organizaciones con las DLS y con las alcaldías.

En general el nivel de discusión de los informes es bastante elevado, lo que es una muestra de la disponibilidad al diálogo entre las partes y la ventana abierta a una mayor expresión de las organizaciones. Esta situación debería estar apoyada por un alto nivel de resolución de problemas o la articulación con las instancias que tienen esa capacidad; como se observa en el cuadro siguiente la aplicación de correctivos aunque es la solución de mayor peso no es completamente dominante, una buena parte son trasladados a organismos de vigilancia y control, y una parte menos gruesa no tiene respuesta alguna. 
Por supuesto la respuesta depende del tema tratado, en proceso de sisbenización y acceso a los servicios, dos temas centrales para las organizaciones, la capacidad de resolución de la instancia que recibe el informe es comparativamente baja y por tanto la calificación que otorga la organización a las actuaciones de esas instancias es poco favorable, se presenta como buena o regular en 33 y $57 \%$ de los casos respectivamente.

Dos temas llaman la atención, el primero es acerca del cumplimiento de las obligaciones por parte de las ARS y el de falta de información del régimen subsidiado. En el primero de ellos se aplicaron los correctivos en el 50 $\%$ de los casos y se traslado a una entidad de control en la parte restante, circunstancia que dejo satisfechas a las organizaciones en todos los casos, esta podría ser considerada como una muestra positiva de las acciones de control social. En el segundo tema por el contrario el nivel de resolución (en DLS y Alcaldías) es muy bajo, en el 43 \% de los casos no habría ninguna solución a la crítica presentada; esta circunstancia se convierte en fuerte obstáculo al ejercicio de la participación y del control y estaría en contravía de una de las principales funciones que deberían ejercer las DLS.

Tabla 3. Organizaciones comunitarias. Trámite de los informes entregados

\begin{tabular}{|c|c|c|c|c|c|}
\hline Temas de Crítica & $\begin{array}{c}\text { Presentado } \\
\%\end{array}$ & $\begin{array}{c}\text { Discutido/ } \\
\text { Propuesto } \\
\%\end{array}$ & $\begin{array}{c}\text { Resultado } \\
\text { Correctivos } \\
\%\end{array}$ & $\begin{array}{c}\text { Traslado } \\
\%\end{array}$ & $\begin{array}{c}\text { Calific Resultado } \\
\text { Bueno-Regular } \\
\%\end{array}$ \\
\hline $\begin{array}{l}\text { Planes salud } \\
\text { municipio }\end{array}$ & 65 & 79 & 27 & 27 & 82 \\
\hline $\begin{array}{l}\text { Proceso de } \\
\text { sisbenización }\end{array}$ & 65 & 80 & 42 & 42 & 33 \\
\hline Carnetización & 40 & 80 & 75 & 0 & 75 \\
\hline Cumplimiento ARS & 35 & 67 & 50 & 50 & 100 \\
\hline $\begin{array}{l}\text { Acceso servicios de } \\
\text { salud }\end{array}$ & 65 & 82 & 43 & 43 & 57 \\
\hline $\begin{array}{l}\text { Falta de información } \\
\text { RS }\end{array}$ & 35 & 70 & 43 & 14 & 57 \\
\hline $\begin{array}{l}\text { Temas de } \\
\text { Propuesta }\end{array}$ & $\begin{array}{c}\text { Presentado } \\
\%\end{array}$ & $\begin{array}{c}\text { Discutido/ } \\
\text { Propuesto } \\
\%\end{array}$ & & $\begin{array}{l}\text { doptó } \\
\text { puesta } \\
\%\end{array}$ & $\begin{array}{c}\text { Calific.Result } \\
\text { Bueno-Regular } \\
\%\end{array}$ \\
\hline $\begin{array}{l}\text { Planes de salud } \\
\text { del municipio } \\
\text { Manejo recursos }\end{array}$ & 40 & 63 & & 50 & 80 \\
\hline $\begin{array}{l}\text { financieros RS } \\
\text { Proceso de }\end{array}$ & 20 & 100 & & 100 & 75 \\
\hline sisbenización & 20 & 100 & & 100 & 75 \\
\hline $\begin{array}{l}\text { Carnetización } \\
\text { Cumplimiento }\end{array}$ & 25 & 80 & & 80 & 80 \\
\hline $\begin{array}{l}\text { ARS } \\
\text { Acceso servicios }\end{array}$ & 40 & 63 & & 40 & 20 \\
\hline de salud & 40 & 75 & & 50 & 100 \\
\hline
\end{tabular}


Tomando en consideración las propuestas de cambio que se hacen en los informes, es preciso señalar que habría más informes de críticas que de aquellos que incluyen propuestas. Así, en el $40 \%$ de las organizaciones que presentaron informes se encontrarían propuestas en torno a planes de salud, cumplimiento de las ARS y acceso a los servicios de salud, en porcentajes menores se encuentran los temas de carnetización, sisbenización manejo de recursos financieros, entre otros. De los resultados aquí presentados se puede derivar que los proponentes están satisfechos con el diálogo establecido con las instituciones sea que se adopten parcial o totalmente sus propuestas. Un caso diferente lo ofrece el tema del cumplimiento de las obligaciones de la ARS, en donde el grado de inclusión de las propuestas es bajo así como la calificación dada por las organizaciones a ese tratamiento del tema.

En general se encuentra que la principal actividad es la difusión de información, es decir, las organizaciones cumplen su papel de correas de transmisión para conocer las necesidades de la población y a su vez dar a conocer el funcionamiento del sistema a la comunidad. Otro ramo importante de acción es la asistencia a cursos, en donde vale la pena destacar los de inspección, vigilancia y control en tanto se orientan fundamentalmente a las veedurías y a los Copacos, es destacable este punto pues mostraría un proceso de especialización del control, en la que se le da prioridad a la ejecución de programas (Tabla 4).

Tabla 4. Actividades de las organizaciones

\begin{tabular}{lcccc}
\hline \multicolumn{1}{c}{ Actividades } & $\begin{array}{c}\text { Veedurías } \\
\%\end{array}$ & $\begin{array}{c}\text { Asociación } \\
\%\end{array}$ & $\begin{array}{c}\text { Copacos } \\
\%\end{array}$ & $\begin{array}{c}\text { JAC } \\
\%\end{array}$ \\
\hline Difusión información & 85 & 86 & 80 & 77 \\
Cursos iniciativa organización & 46 & 24 & 80 & 31 \\
Cursos DLS, ARS, IPS & 77 & 41 & 40 & 54 \\
Talleres control social & 54 & 45 & 80 & 23 \\
Asistencia cursos & 46 & 45 & 60 & 39 \\
Asistencia cursos IVC & 62 & 38 & 60 & 23 \\
Otros & 15 & 7 & 0 & 31 \\
Entrega Informes & 39 & 41 & 60 & 46 \\
\hline
\end{tabular}

Control social ciudadano. En cumplimiento del decreto 1757/94 las EPS e IPS deben establecer un servicio de atención a los afiliados y vinculados al SGSSS. Por su parte, los niveles de dirección municipal, distrital y departamental de SGSSS deben organizar un servicio de atención a la comunidad a través de las dependencias de participación social para canalizar y resolver 
las peticiones e inquietudes en salud de los ciudadanos. Además de este propósito central deben velar porque las IPS establezcan los mecanismos de atención a los usuarios y canalicen adecuadamente sus peticiones, atender y canalizar las veedurías en salud, controlar la adecuada canalización y resolución de inquietudes y peticiones de los ciudadanos ante las EPS, exigir que las EPS e IPS entreguen información a las oficinas de atención a la comunidad y que esas instituciones apliquen los correctivos, elaborar consolidados de las inquietudes y demandas indicando las instituciones y/o dependencia responsable de absolver dichas demandas y la solución que se le dio al caso.

Este es un proceso que avanza en forma desigual si se tiene en cuenta la categoría del municipio, en los municipios medianos y pequeños existe un porcentaje significativo de DLS que no cuentan con mecanismos para recibir las quejas y predominan las DLS que aun cuando no han creado una oficina designan una persona para esa labor.

Una situación más favorable se presenta en las IPS de los municipios grandes y medianos en las cuales el mayor porcentaje lo tiene la presencia de una oficina de atención al usuario. Circunstancia distinta se manifiesta en los municipios pequeños en los que la instalación de un buzón de sugerencias es el principal mecanismo para percibir las inconformidades de la comunidad; sorprende que precisamente en los municipios en los cuales la población manifiesta una baja proclividad a la escritura, exista un buzón de sugerencias como canalizador de quejas. Si en el caso de los municipios pequeños a la medida anterior se suma el porcentaje en el que no existe instrumento alguno (20\%) se tendría que apenas en la mitad de los municipios la comunidad tiene opción de presentar sus quejas

La debilidad de las DLS en la conformación del servicio de atención a la comunidad se torna preocupante al considerar que es la institución que recibe la mayor cantidad de quejas en el municipio. En su proceso de mejoramiento se debe abrir espacio a la sistematización de las inquietudes, puesto que en significativo número de instituciones no se cuenta con registros que permitan observar la dinámica de este tipo de participación social, condición que se puede aplicar a los demás actores del sistema. En el caso de los personeros es notoria su baja participación en los municipios pequeños, puesto que el 24 $\%$ de ellos no recibe quejas; de la porción que recibe las inquietudes el 14 \% no lleva registro alguno.

De la composición de las quejas se puede establecer que las más frecuentes se refieren a las posibilidades reales de acceder al servicio; aquellas que tiene que ver con el funcionamiento del sistema, como cumplimiento de los 
programas de prevención y promoción, explicación de derechos, obstáculos a la participación, atención de reclamos, interferencia política y presiones en la afiliación, registran bajas frecuencias. Esta conclusión es consistente con la obtenida a través de las encuestas de inspección vigilancia y control, de la cual se deriva que los principales problemas se refieren al acceso al sistema y a las fallas en la prestación de servicios.

Un elemento que vale la pena destacar es la solución sobre la marcha, en la mayoría de los casos la queja tiene como respuesta la resolución del problema de quien se queja; el porcentaje de casos que dan lugar a investigación o que son trasladados a una instancia de control cubren menos de la tercera parte; y los que generan sanción son prácticamente inexistentes. La falta de un tratamiento ulterior de la queja no permite actuaciones que den lugar a soluciones globales y permanentes a los problemas que se presentan. Adicionalmente se puede observar que la recurrencia de los individuos ante las instituciones en especial la DLS para instaurar una queja sobre acceso y oportunidad es una muestra de la dificultad o lentitud de los mecanismos de mercado para ejercer sanción, es decir, el individuo busca a través de la instituciones la solución de su problema y no adelanta un traslado de IPS o ARS para ejercer sus derechos como usuario.

En el caso de las IPS la queja más recurrente tiene que ver con el acceso a los servicios, los mecanismos para lograr una cita se constituyen en el principal obstáculo; como se había señalado en otra sección de este capítulo éste se ha constituido en uno de los principales instrumentos de las IPS para provocar racionamiento en la atención y con ello mantener un equilibrio financiero, lo cual se puede contrastar con el tipo de solución que se le da al problema, en cerca del $50 \%$ de los casos la solución es individual, a un cuando en el 34 $\%$ de los casos se ha procedido a cambios en los procesos para admisión de pacientes. Otro instrumento de restricción en el acceso es el de insumos insuficientes el cual se resuelva básicamente atendiendo al individuo que se queja y cerca de un $15 \%$ de las quejas quedan sin solución. Respecto a las IPS es pertinente señalar que de los actores del sistema es el que más bajo porcentaje de soluciones individuales presenta y en contrapartida tiene una mayor recurrencia en las sanciones. Vale la pena también señalar su poca efectividad en la solución de casos que tienen que ver con la deficiente atención, la negligencia en el servicio, los accidentes y la negación del servicio; esta situación es preocupante por cuanto mostraría la poca capacidad de presión que tienen los individuos frente a la institución.

Por su parte, en la Personería y en la DLS la queja más frecuente en el conjunto de municipios es la atinente a la no sisbenización. Al igual que en 
la situación de las IPS el problema es de acceso, solo que en este caso es al primer escalón de la escalera que conduce a la obtención del subsidio. En esta misma dirección la segunda queja en frecuencia se refiere a la negación del servicio médico. Vale la pena destacar también las reclamaciones que hacen los afiliados cuando la ARS no entrega los carnés, en tanto su proporción no es despreciable (47\%), resulta significativo también que estas quejas no conducen a acciones que eviten su repetición, sino que como la generalidad de las soluciones se trata de satisfacer al individuo que se queja.

Institucionalización de la política de promoción de la participación comunitaria

La legislación estableció que los recursos necesarios para la promoción de la participación social debían ser incluidos en los presupuestos de los diversos niveles territoriales y el conjunto de instituciones del sistema. Por tal razón las direcciones departamentales allegarían los recursos financieros para cumplir con esa responsabilidad y coordinarían con las EPS las acciones que se financiarían con los recursos destinados para tal fin en el Plan Obligatorio de Salud-POS. Las direcciones municipales de salud coordinarían con las dependencias de desarrollo comunitario, las personerías, las contralorías municipales y los demás sectores la financiación de las acciones bajo su responsabilidad, el gobierno municipal podría aportar recursos adicionales.

Se observó que la proporción de DLS que tiene claramente estipulado cual es la asignación presupuestal para el trabajo comunitario es muy baja. En general, no hay discriminación de estos recursos sino que se toman de la asignación para el PAB; el porcentaje de municipios en los cuales no se tiene recursos o no se conoce su asignación es del $53 \%$; esta situación es más severa en el caso de municipios pequeños y medianos, en los cuales ese desconocimiento cubre al $64 \%$ de los municipios encuestados.

A la baja disponibilidad de recursos por parte de la DLS se suma las limitadas condiciones en las que operan las organizaciones comunitarias. Son muy pocas las organizaciones que cuentan con oficina y equipos de oficina y en los casos en que existen son, fundamentalmente, aportados por instituciones del sistema. Es importante notar que sólo el 32 \% de las organizaciones han asignado funcionarios que se ocupan de las relaciones con los miembros; esta situación sugiere informalidad en el funcionamiento de tales grupos, lo cual conduce a dificultades en la convocatoria de la participación, dificulta el correaje de información y restringe las posibilidades de promover la participación a través de estas organizaciones. 
Otro elemento que obstaculiza el desempeño de las organizaciones es la falta de un lugar para llevar a cabo las reuniones; cerca de la tercera parte de las organizaciones no cuenta con tal recurso, con lo cual debe recurrir a los espacios abiertos o a las casas de sus miembros, situación que también explicaría los bajos niveles de reuniones adelantadas. En la casi totalidad de los casos en los cuales se dispone de un lugar de reunión este es aportado por alguna de las instituciones del sistema, particularmente la Alcaldía o una IPS.

En algunas experiencias de participación se concluye que falta financiación para los procesos comunitarios y que en la práctica se manifiesta una deficiente administración de los recursos. Problemas más agudos que tienen que ver con la institucionalización de una política de organización comunitaria se refieren a las difíciles relaciones que existen entre la administración municipal y las organizaciones comunitarias, especialmente en el período inicial. A la falta de un adiestramiento en la promoción de la organización comunitaria de la burocracia, se suma una actitud defensiva, en particular cuando la organización social ejerce sobre todo las tareas de fiscalización. Igualmente, a este tipo de relación contribuye la falta de una tradición en procesos de concurrencia y concertación. En muchos casos subsiste una visión legalista del proceso comunitario que no permite generar un desarrollo técnico y social, por tanto su alcance es muy limitado (15).

Otro elemento de significativa importancia es la falta de coordinación interinstitucional para potenciar las acciones de la comunidad. Como se señaló en páginas anteriores cada institución establece relaciones exclusivamente con su asociación; igualmente, en el caso de las quejas cada uno de los actores intenta dar respuesta a las personas que se quejan. Dentro de esta forma de operación no existen los vínculos necesarios para aprovechar las experiencias institucionales que conduzcan a fortalecer las relaciones entre la comunidad y las entidades, pero tampoco se permite generar instrumentos que hagan de la participación una fuente de instrumentos para adelantar la planeación de las actividades.

En esta perspectiva resulta interesante el papel del personero, que se ha convertido en un actor central a la hora de canalizar las quejas no sólo de la comunidad sino también de las instituciones. Sólo en muy contados casos el personero hace parte del Copaco, órgano que podría aprovechar las experiencias de este actor.

Si la coordinación es elemento central dentro de los actores del sistema de salud, tampoco lo es hacia fuera; así se está desaprovechando el aprendizaje 
de otros grupos de población y de otras instituciones. En los municipios en los cuales no se ha creado la DLS, el papel de promover la participación comunitaria recae sobre la Alcaldía; si bien esta situación permitiría una mayor vinculación de la comunidad y de los organismos administrativos, en la práctica su baja capacidad operativa no permite que el conjunto de las organizaciones avance y se establecen prioridades, que dependerán en gran medida de la capacidad de auto-organización comunitaria. En esta misma dirección se puede señalar que el mayor contacto lo ejercen los promotores de desarrollo, quienes no son capacitados en materia de salud, de funcionamiento del régimen subsidiado, ni en ejercicio del control social en salud.

Una mayor integración institucional aportaría enormes beneficios, no sólo en términos de mejoras en la planeación sino también en un avance más rápido hacia la elevación de las capacidades participativas de la comunidad.

\section{Características de las organizaciones comunitarias}

Entre las potencialidades de la participación ciudadana en la esfera de lo público-estatal se encuentra la posibilidad de incrementar la representación social en la conducción de los asuntos públicos. Sin embargo, la manera como se implemente la participación podrá dar lugar a fenómenos adversos como la corporativización del aparato estatal o una mayor despolitización social, situaciones que redundarían en el fortalecimiento de las asimetrías en la representación política y social (16).

De allí que la posibilidad de establecer relaciones virtuosas entre el Estado y la sociedad depende de que en el proceso de institucionalización de la participación estén presentes los principios de igualdad y libertad para todos. Así, la conformación de organizaciones comprometidas con el fortalecimiento de la democracia, incluso en su interior, es una condición del desarrollo de la institucionalidad de representación social; por ello se debe propender por organizaciones que se basen en relaciones horizontales de reciprocidad, cooperación voluntaria y no reforzar las asimetrías de poder (16).

De los elementos que dan cuenta de la configuración de las organizaciones se puede derivar que existe un considerable grado de autonomía. En general, para pertenecer a la organización no se debe cumplir ningún requisito distinto al de ser miembro de la comunidad o ser usuario; en el caso de las veedurías y en el de las asociaciones de usuarios existe un pequeño porcentaje en el cual se presenta nominación por parte de la alcaldía, la DLS, la IPS 
o la ARS para hacer parte de la organización lo cual es un reflejo de la falta de espacios de participación y consulta a la comunidad (Figura 5).

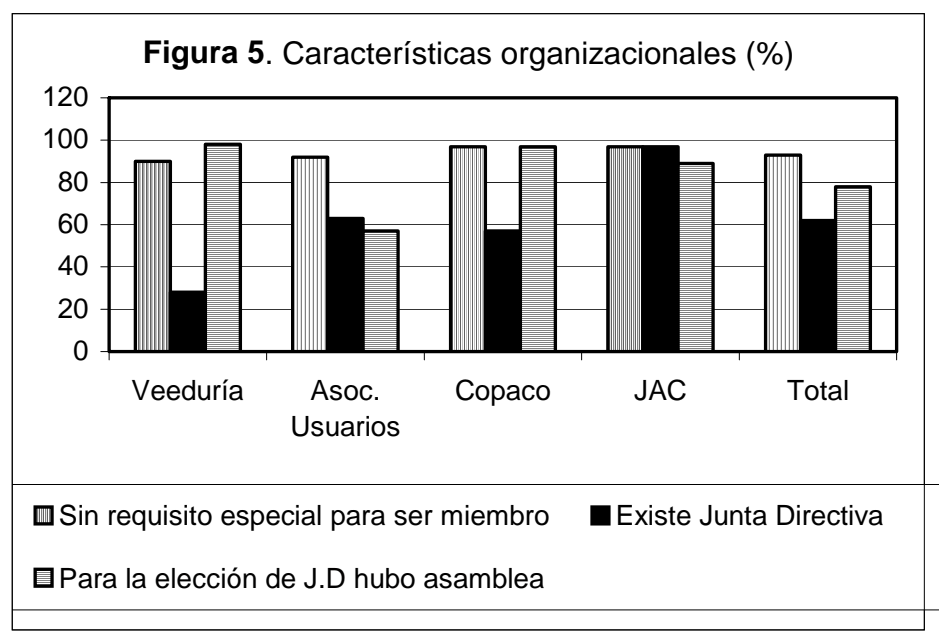

Una muestra del tamaño y fortaleza de la estructura organizativa de estos grupos comunitarios se puede apreciar en la conformación de juntas directivas. La mayor tradición que reviste la organización comunitaria a través de las juntas de acción comunal redunda en que la totalidad poseen una junta directiva, en la mayoría de los casos elegida por convocatoria de asamblea de miembros.

Preocupa el caso de las asociaciones de usuarios en las cuales apenas el 66 \% posee junta directiva y en el $60 \%$ de los casos ésta ha sido elegida convocando asamblea. Esta circunstancia pone de manifiesto el carácter informal con que actúan muchas de estas organizaciones, lo que en buena parte de los casos refleja la existencia de la organización más no su operatividad como mecanismo de control social o de vínculo entre los usuarios y las instituciones. De igual manera, la elección de junta directiva sin que medie una asamblea de asociados muestra la interacción de dos fenómenos: a) las limitaciones en los canales de participación efectiva, producto de la intervención de las entidades al considerar las organizaciones comunitarias como instrumento que le permita un manejo más eficiente de sus programas o de su relación con los usuarios; b) la reticencia de los usuarios a participar, derivada de la falta de credibilidad en el reconocimiento que las instituciones del sistema deben a 
la participación comunitaria, pero también surgida de la falta de compromiso de la comunidad en procesos que desbordan el beneficio individual.

Respecto a las veedurías es preciso señalar que no se espera que tengan junta directiva dado el carácter que les fue impuesto, es decir, puede ser participación individual o colectiva, incluyendo en esta última comités de pocos miembros. De ahí que los resultados de la encuesta mostrarían la existencia de veeduría con un considerable número de miembros, lo que da lugar a la conformación de juntas directivas. Esta apreciación sería aplicable también a los Copacos, el nombramiento de una junta directiva depende del número de miembros que contenga la organización, en los casos en los cuales se creo esta figura hubo convocatoria de asamblea de miembros.

Una forma de aproximarse al grado de actividad de las organizaciones comunitarias es la frecuencia de las reuniones que se llevan a cabo, distintas de las que realizan las Juntas Directivas. La proporción de organizaciones que no realizaron ninguna reunión es bastante bajo y se presenta en las asociaciones y veedurías. Pero el más alto número de reuniones al año oscila entre 1 a 6 . Tal frecuencia puede ser un indicador del restringido contacto que se mantiene entre los miembros, ya sea porque no existe una junta directiva que impulse el proceso de cohesión o por las limitaciones en los vínculos entre la junta directiva y los miembros.

\section{CONCLUSIONES}

En Colombia, la Constitución de 1991, al establecer la obligatoriedad de promover la participación social, se convirtió en punto de encuentro entre los movimientos sociales que propendían por un mayor espacio en la esfera política y en la gestión pública y las instituciones estatales que estaban generando mecanismos participativos.

No obstante, la discusión en torno al significado y el alcance de la participación social no fue agotada con la promulgación de la carta constitucional. Inserta en los propósitos de profundizar la democracia y en la propia democratización del Estado, la participación social contiene un alto componente político, es decir, se trata de la transferencia de una parte del poder a los sectores que antes estaban al margen en la toma de decisiones estatales. Así, la forma como sea ejercida esa participación dará lugar al fortalecimiento de la democracia representativa o al avance de la participativa; la diferencia central se observaría en los procesos de discusión y configuración de los planes estatales. 
En el desarrollo de los preceptos constitucionales en el ramo de la salud, se ha puesto en marcha un modelo de participación en el cual la colectividad es entendida como el conjunto de individuos que comparten un interés común y por ello la acción colectiva sería la expresión de los individuos que buscan la maximización del beneficio en la provisión de un bien o en la generación de políticas. De esta manera, las funciones de la organización se orientarían al logro de la eficiencia tanto en la asignación de los recursos como en la gestión.

Se encontró que en concordancia con la legislación la comunidad hace presencia en el campo de la salud básicamente a través de las asociaciones de usuarios y las veedurías. Pero, la generación de procesos participativos "desde arriba”, en el caso de salud no tendría una contraparte "desde abajo", en tanto el número de experiencias organizativas distintas a las estipuladas por la legislación es bastante reducido.

Otra característica central del modelo institucional es el predominio de una perspectiva fiscalizadora de los recursos públicos. En la medida en que el Estado ha concebido la estrategia de mercado como la mejor forma de asignar los recursos y los receptores de la política social son considerados como consumidores, el reto es establecer un balance de oferta y demanda para garantizar eficiencia y eficacia en la aplicación de los recursos y transparencia en la gestión pública. De allí que la comunidad de usuarios tiene la misión de velar porque se lleve a cabo una correcta asignación de los recursos provistos por el Estado.

Una manera de apreciar esta tendencia es la configuración de las formas de participación. Así, el mecanismo de representación de la comunidad en las juntas directivas opera para las IPS y EPS públicas o mixtas; es decir, no hay ninguna injerencia en el ámbito privado. Igualmente, la conformación de asociaciones de usuarios compete a los asegurados, con lo cual los vinculados estarían excluidos de la participación y la representación. Otro ejemplo del énfasis fiscalizador lo aportan las veedurías, no sólo en términos de la importancia que se le otorga como mecanismo de control, sino también por las funciones que se le han asignado.

Al evaluar algunos de los resultados de la aplicación de esta estrategia de participación social en salud se pueden destacar tres características: hay importantes avances en la promoción de la participación, pero no en control social; existe dispersión y atomización del control social; y se manifiesta una debilidad de la participación como política institucional. 
Respecto al primer tema se puede concluir que ha existido una respuesta favorable por parte los municipios a la obligación de promover las formas organizativas de la comunidad en lo que a salud se refiere. Sin lugar a dudas, la creación de la DLS constituye un importante impulso a la participación social en salud y en aquellos municipios en los que no existe este ente territorial se hace evidente un menor esfuerzo en promoción y un menor número de organizaciones comunitarias actuantes.

Al tomar en cuenta las acciones desarrolladas en control social el panorama cambia. La convocatoria de las instituciones del sistema a las organizaciones comunitarias es considerablemente bajo al igual que la discusión de los informes presentados por tales organizaciones. Esta situación ilustraría que buena parte de la promoción del proceso participativo está en su fase inicial de difusión del funcionamiento del sistema y conformación de organizaciones, pero no se ha dado el paso a una verdadera interlocución entre los actores.

La mayor contribución de la comunidad y de las asociaciones de usuarios es el aporte de información; de estos grupos se extraen los datos que permiten determinar las necesidades, inconformidades o preferencias del grupo poblacional y las asociaciones se aprovechan como vehículo en la difusión de las condiciones de operación del sistema y mecanismo de acercamiento a los potenciales demandantes de servicios. Menos intensa es la consulta sobre políticas y programas y lo es aún menos la concertación de políticas.

La participación se intensifica en el control a la ejecución de programas y proyectos, las prácticas de coadministración de algunas de las instancias o acciones de un programa y en la ejecución de las acciones de los programas. Este último paso es bastante claro en la integración de la comunidad en los planes de prevención y promoción, en su llamado a contribuir al proceso de priorización de potenciales beneficiarios y a la carnetización (en donde los miembros de la asociación o los líderes comunitarios contribuyen), en la configuración de la oficina de atención a la comunidad y su operación por parte de las asociaciones, entre otros.

La falta de profundización del proceso de control social está ligada a las capacidades que desarrollan las organizaciones. Se encontró que estos grupos dedican buena parte de sus esfuerzos a los problemas derivados de la sobrevivencia de la organización y a la difusión de información sobre la existencia y funcionamiento del régimen subsidiado y aún no se ha dado un paso decidido hacia el ejercicio del control social. 
Respecto a la atomización y dispersión del control social es preciso anotar que se refiere tanto a los agentes que pueden ejercerlo y a la manera como se manifiestan las acciones de control. Dentro de la pirámide participativa que estableció la legislación; desde todos estos entes se puede ejercer control. Esta jerarquización debería dar lugar a un tratamiento sistemático de las dificultades y retos del sector salud de acuerdo con los niveles en que se lleva a cabo esta participación.

Se hizo evidente la falta de comunicación entre las diferentes instancias de la estructura piramidal- en la base se encuentran los individuos, luego las asociaciones, más arriba la representación en juntas directivas y finalmente en Copacos y consejos territoriales- lo que a su vez se traduce en la presencia de relaciones de naturaleza bilateral; es decir, sólo se conoce al interlocutor más directo. De manera similar se encuentra un bajo nivel de relación entre las organizaciones comunitarias del sector y aún con los otros sectores. Esta estructura atomística de la participación se refuerza en el hecho de que las quejas individuales son el mecanismo de control más extendido, pero su tratamiento por parte de las distintas instancias del sistema no permite convertirlas en fuente información para la detectar problemas recurrentes o compartidos por distintos agentes, con lo cual tampoco se constituyen en variables que orientes las discusiones sobre la evolución del sistema en el municipio.

La última característica señalada se refiere a los escasos recursos con que cuentan los programas de PPC y las organizaciones comunitarias.

El carácter de derecho social que tiene la salud implica un mayor grado de compromiso de la población y por lo tanto la puesta en marcha de mecanismos de control que desborden la esfera fiscalizadora y permitan el desarrollo de una capacidad propositiva. Por ello es preciso iniciar un proceso de aprendizaje en el cual se parta por esclarecer la calidad de las relaciones entre la participación y los programas estatales y los instrumentos que permitirían mejorarla; igualmente, es preciso establecer un sistema de capacitación para líderes a través del cual no sólo se aporte información específica sino que se apoye en el desarrollo de capacidades.

En la misma dirección se puede avanzar hacia la superación del concepto de comunidad o colectividad para inscribirse en el de ciudadanía al cual corresponden los derechos sociales. Así, los criterios de solidaridad y equidad se constituirían en el faro que guía la participación y el control. De esta manera se convierte en compromiso de todos los ciudadanos contribuir al debate en torno a los planes y a las directrices que debe seguir el sistema de salud, 
para que este se pueda evaluar en sus dimensiones de efectividad, eficiencia y eficacia

\section{REFERENCIAS}

1. Campos Y. Elementos para una participación comunitaria. Fescol. Bogotá.

2. Eatsman JM. La participación y el dilema del prisionero. En: Manual para participar en el desarrollo institucional. Participación en la vida socioeconómica y el desarrollo colectivo. Tomo 4. Bogotá: Consejería Presidencial para el Desarrollo Institucional; 1996.

3. Veeduría Distrital. Guías para el control social. Bogotá.

4. Esguerra NB. Los programas gubernamentales y la participación comunitaria en la Colombia actual. Un modelo de análisis. En: Participación comunitaria y cambio social en Colombia. Memorias del seminario nacional sobre participación comunitaria. Villa de Leyva: DNP-Unicef-Cinep-ACS; 1986.

5. Restrepo D. El cáliz de la participación. Relaciones Estado sociedad civil en el campo social. Una reflexión desde el caso colombiano. Bogotá; 1995.

6. Racelis M. Movilizando a la población para el desarrollo social. Enfoques y técnicas para la participación popular. En: Bernardo Klisberg (comp.). Pobreza un tema impostergable. Nuevas respuestas a nivel mundial. México: CLADFCE-PNUD; 1993.

7. Ochoa D, Restrepo D. El estado del arte de la descentralización política y de la oferta pública de participación ciudadana comunitaria. En: Diez años de descentralización. Resultados y perspectivas. Bogotá: Fescol; 1994. p. 132.

8. Acevedo B. El control social y la participación ciudadana en las relaciones sociedad Estado. Un modelo para armar. Bogotá: Reunirse; 1998.

9. Veeduría Distrital. Gestión pública y control. Bogotá.

10. Ministerio de Salud de Colombia. Políticas de participación social en salud. Bogotá; 1997.

11. Béjean S. Economie du système de santé. Du marché á l'organisation. Economica, Paris; 1994. p. 166.

12. Granovetter M. Les institutions conventions. Paris: PUF; 1994.

13. Restrepo D. Eslabones y precipicios entre participación y democracia. Cuadernos de Economía. Universidad Nacional de Colombia. No.28, 1998.

14. Arévalo D, Martínez F, Rodríguez O. (Ed.) ¿Ha mejorado el acceso en salud?. Evaluación de los procesos del Régimen Subsidiado. Bogotá: Universidad Nacional de Colombia, Ministerio de Salud; 2002.

15. Fescol-Gehos-Presidencia de la República-Instituto FES de Liderazgo ¿ $Y$ cómo va la reforma? Memorias del Foro nacional de avances en el desarrollo del SGSSS. Bogotá; 1996.

16. Cunill NG. Repensando lo público a través de la sociedad. Nuevas formas de gestión pública y representación social. Caracas: CLAD; 1997. p.16. 